\title{
GCU
}

Glasgow Caledonian

University

University for the Common Good

\section{Influence of sustained loading on fracture properties of concrete}

Dong, Wei; Zhang, Xue; Zhang, BinSheng; Wu, Qiao

Published in:

Engineering Fracture Mechanics

DOI:

10.1016/j.engfracmech.2018.07.034

Publication date:

2018

Document Version

Author accepted manuscript

Link to publication in ResearchOnline

Citation for published version (Harvard):

Dong, W, Zhang, X, Zhang, B \& Wu, Q 2018, 'Influence of sustained loading on fracture properties of concrete', Engineering Fracture Mechanics, vol. 200, pp. 134-145. https://doi.org/10.1016/j.engfracmech.2018.07.034

\section{General rights}

Copyright and moral rights for the publications made accessible in the public portal are retained by the authors and/or other copyright owners and it is a condition of accessing publications that users recognise and abide by the legal requirements associated with these rights.

Take down policy

If you believe that this document breaches copyright please view our takedown policy at https://edshare.gcu.ac.uk/id/eprint/5179 for details of how to contact us. 
$3{ }^{1}$ Associate Professor, State Key Laboratory of Coastal and Offshore Engineering, Dalian University

4 of Technology, Dalian 116024, P. R. China. E-mail: dongwei@dlut.edu.cn

$5 *$ Corresponding author

$6{ }^{2}$ Lecturer, State Key Laboratory of Coastal and Offshore Engineering, Dalian University of

7 Technology, Dalian 116024, P. R. China. E-mail: Xuezhang@dlut.edu.cn

$8{ }^{3}$ Professor, Department of Construction and Surveying, School of Engineering and Built

9 Environment, Glasgow Caledonian University, Glasgow G4 0BA, Scotland, United Kingdom. E-mail:

10 Ben.Zhang@gcu.ac.uk

$11{ }^{4}$ Postgratuate student, State Key Laboratory of Coastal and Offshore Engineering, Dalian University 12 of Technology, Dalian 116024, P. R. China. E-mail: 15129485818@mail.dlut.edu.cn 
To investigate the effects of sustained loading on the fracture properties of concrete, basic creep and three-point bending (TPB) tests were conducted on the pre-notched beams. The specimens were first subjected to two sustained loading levels, i.e. 30\% peak load and the initial cracking load over 115 days. Then, they were moved out from the loading frames and tested under TPB loading until failure. The critical crack propagation length $\left(\Delta a_{\mathrm{c}}\right)$, the peak load $\left(P_{\max }\right)$ and the fracture energy $\left(G_{\mathrm{f}}\right)$ were measured in the tests, and the unstable fracture toughness $\left(K_{\mathrm{IC}}^{\mathrm{un}}\right)$ was calculated accordingly. Furthermore, based on the load-displacement curves obtained in the TPB tests, the energy dissipation was derived using the modified J-integral method. By enforcing balance between the energy dissipated and the energy caused by the fictitious cohesive force acting on the fracture process zone, the tension-softening constitutive laws under the two sustained loading levels were established and also simplified as bilinear forms for practical applications. Finally, the effects of sustained loading on the fracture properties were examined by comparing with the tested results from the aging specimens in the static TPB tests. The test results indicate that low sustained loading had no effects on all fracture properties of concrete investigated in this study, while under high sustained loading, $\Delta a_{\mathrm{c}}$ and $K_{\mathrm{IC}}^{\mathrm{un}}$ increased and $G_{\mathrm{f}}$ and $P_{\max }$ almost remained unchanged. Meanwhile, a smaller free-stress crack opening displacement was obtained under the high sustained loading level, which indicates a shorter FPZ length formed, resulting in the increase in brittleness of concrete.

Keywords: Sustained loading; Concrete; Fracture properties; Tension-softening constitutive law. 


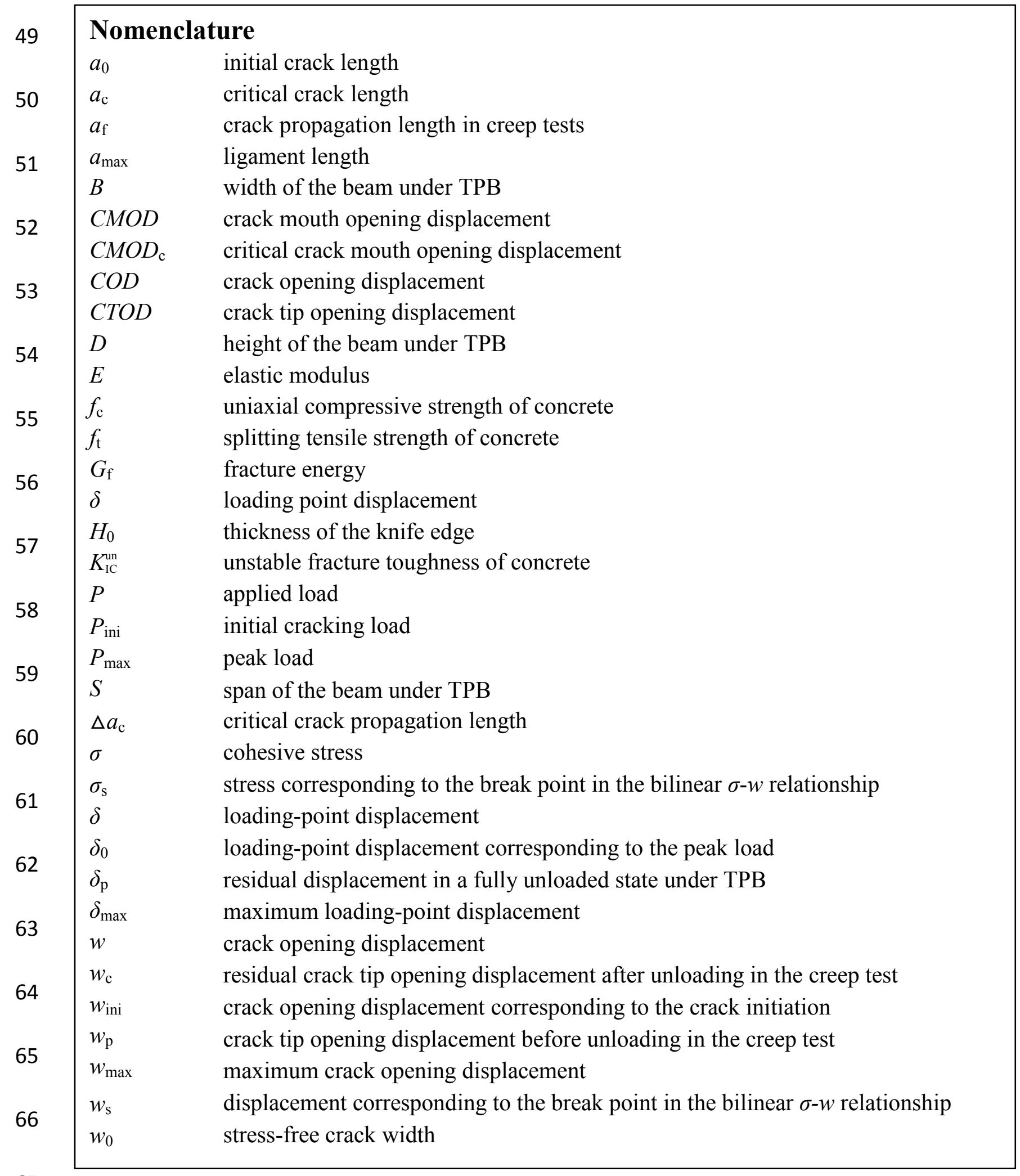

\section{7}




\section{Introduction}

71 In practical engineering, most concrete structures in service are under sustained loading, such as gravity dams, protecting shells in nuclear power stations, cooling towers in thermal power plants, etc. Usually, behaviour of concrete is considered to be viscoelastic under low loading levels [1]. In contrast, cracks initiate, develop and interact with viscoelasticity of concrete under high loading levels, producing high short-term and long-term deformations on concrete structures and largely influencing their load-carrying capacity and durability [2]. Also, the strain of concrete at the crack tip may be large enough to reach its ultimate tensile value, resulting in the initiation and development of new cracks even though the stress level of concrete is below its static tensile strength [3]. It is also possible for existing cracks to propagate unstably when the stress intensity factor (SIF) at the crack tip is even below the fracture toughness [2]. These time-dependent behaviours for concrete are associated with the variations of the cohesive stress in the fracture process zone (FPZ) over time, where the stress relaxation occurs and the released strain energy booms the crack propagation [3, 4]. Hence, the experimental results from static tests cannot be directly used to comprehensively analyse the fracture behaviour of concrete structures under sustained loading. Therefore, it is significant to further explore the fracture properties of concrete under sustained loading so that the crack propagation process and load-carrying capacity of concrete can be predicted more precisely.

87 In the past decades, many attempts have been made to extensively investigate the time-dependent 88 fracture behaviour of concrete and associate the fracture characteristics of concrete with the time by means of loading rate [5], crack growth rate [6] and long-term loading time [7, 8]. Accordingly, the 
91 and long-term load on the deformation [9], failure time [10] and residual loading capacity [11] have

92 been investigated. In the case of sustained loading, it has been widely known that the loading level

93 has a significant effect on the fracture properties of concrete. According to the research by Omar et

94 al. [12], the crack propagation under high sustained loading could reduce the cracking resistance,

95 which is similar to the case of fracture at a slow loading rate. The descending branch of a static

96 load-displacement curve can be regarded as the envelope of the creep fracture curves under high

97 sustained loading, so that the fracture energies under sustained loading and static loading are close

98 to each other [13]. Saliba $[14,15]$ indicated that, due to the consolidation of hardened cement paste,

99 concrete was strengthened under sustained loading so that measured fracture energy and strength

100 increased slightly after a sustained loading is applied. However, the crack propagation during

101 sustained loading was normally not considered in the determination of the fracture energy [14, 15],

102 which may result in some deviations from the true value for the derived fracture energy from the

103 fracture tests. Compared with the critical crack propagation length under the static loading, the 104 crack propagation length after the creep under a high loading level could be different, which 105 accordingly influences the determination of the unstable fracture toughness. Therefore, it is 106 significantly important to study the crack propagation under high sustained loading so that the 107 corresponding influence on the fracture properties of concrete, including the fracture energy and 108 unstable fracture toughness, can be determined more accurately.

109 According to the fictitious crack model [16], there exists a fracture process zone (FPZ) ahead the 110 microcracks, which characterises the strain softening and localisation behaviour through the 111 relationship of the cohesive stress $\sigma$ with the crack opening displacement $w$. Compared with the 
113 be observed in the creep fracture tests $[12,14]$. This can also be explained by the development of 114 microcracks under the creep, the prestressing in the upper zone of specimens [14], and the relaxation 115 of the cohesive stress in the FPZ [12]. Due to the time-dependency of the fracture process zone, 116 much attention has been paid to establishing an appropriate constitutive law to characterise the $\sigma$ - $w$ 117 relationship. So far, three typical methods have been proposed to analyse time-dependent tension 118 softening behaviour of concrete. The first one is based on the activation energy and loading rate 119 dependent softening, which is appropriate when the effect of loading rate is significant [17]. The 120 second one considers the viscosity characteristics of concrete materials by applying the rheological 121 theory into the fictitious crack model $[18,19]$. The third one combines the rheological theory with 122 the micromechanical homogenisation to investigate the time-dependent tension softening behaviour 123 in the FPZ $[20,21]$. It should be mentioned that all three methods focus on the time-dependent $\sigma$ - $w$ 124 relationships of the FPZ during the crack propagation process under sustained loading. Considering 125 some concrete structures do not fail or initial cracks remain stable under sustained loading, the 126 effects of sustained loading on the tension softening characteristics of the uncracked zone also need 127 to be explored further. Therefore, to assess the load-carrying capacity of concrete structures under 128 or after sustained loading, it is essentially important to establish the tension softening constitutive 129 laws for concrete along the uncracked ligament.

130 Thus, the objective of this paper was to investigate the influence of different sustained loading levels 131 on the fracture properties and tension softening constitutive law of concrete. Firstly, the basic creep 132 tests were conducted under three-point bending (TPB) on the concrete beams at $30 \%$ of the peak 
133 load and also at the initial cracking load for 115 days. Thereafter, these specimens were unloaded 134 from the creep frames and then subjected to TPB loading immediately until failure. Based on the 135 experimental results of the TPB tests, a tension-softening constitutive law for the specimens after 136 being subjected to sustained loading, i.e. creep, could be established by considering the effects of the 137 microcracks which formed during the creep stage. Finally, the effect of sustained loading on the 138 fractural parameters and tension-softening constitutive law could be explored by comparing with the 139 results obtained from the static loading tests on the matured specimens.

\section{Experimental Program}

\subsection{Preparation of the specimens}

142 The dimensions of the concrete specimens for both basic creep tests and TPB tests were $500 \mathrm{~mm} \times$

$143100 \mathrm{~mm} \times 100 \mathrm{~mm}$ (length $\times$ width $\times$ depth) with a $30-\mathrm{mm}$ pre-notch. The mix proportions of the concrete were $1: 0.60: 2.01: 3.74$ (cement : water : sand : aggregate) by weight and the maximum coarse aggregate size was $10 \mathrm{~mm}$. The specimens were demoulded 24 hours after casting and then cured in the standard curing room with $23^{\circ} \mathrm{C}$ and $90 \%$ relative humidity for three months to avoid possible early age autogenous shrinkage in the creep tests. The material properties of the concrete at the age of 28 days are listed in Table 1 , where $E, \rho, f_{\mathrm{t}}$ and $f_{\mathrm{c}}$ denote the Young's modulus, density, splitting tensile and uniaxial compressive strength of concrete, respectively. In order to calibrate the applied load in the creep tests, three-point bending tests were performed to determine the peak load the age of 28 days. 
Table 1 Material properties of concrete at the age of 28 days

\begin{tabular}{ccccc}
\hline Material property & $\begin{array}{c}E \\
(\mathrm{GPa})\end{array}$ & $\begin{array}{c}\rho \\
\left(\mathrm{kg} / \mathrm{m}^{3}\right)\end{array}$ & $\begin{array}{c}f_{\mathrm{t}} \\
(\mathrm{MPa})\end{array}$ & $\begin{array}{c}f_{\mathrm{c}} \\
(\mathrm{MPa})\end{array}$ \\
\hline Quantity & 32.9 & 2450 & 2.50 & 54.8 \\
\hline
\end{tabular}

\subsection{Creep tests}

156 A steel loading frame was designed for performing the creep tests and the experimental set-up is

157 illustrated in Fig.1. The load cell was connected onto a bolt and the load was applied by turning the

158 bolt. The data acquisition system with a digital display was used to record the real-time load. The

159 creep tests were conducted inside an environmental chamber with $23^{\circ} \mathrm{C}$ and $60 \%$ relative humidity.

160 To ensure only the basic creep to be measured in the tests, double-layer aluminium tape was utilised

161 to seal the surfaces of the specimens to prevent the moisture evaporation.

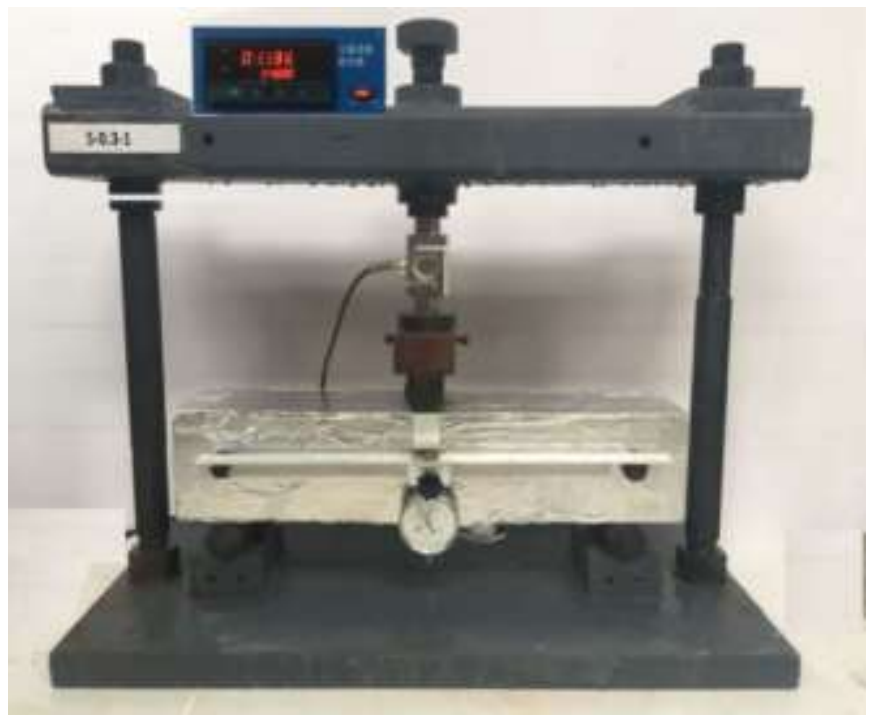

Fig. 1. Set-up of the creep test

164 To investigate the creep behaviour at various loading levels, $30 \%$ of $P_{\max }$ and the initial cracking

165 load were applied in the creep tests, respectively. For each load level, three specimens were adopted.

166 For the specimens subjected to $30 \% P_{\max }$, the bolt was turned until the load level of $30 \% \times 3.81 \mathrm{kN}$

$167=1.14 \mathrm{kN}$ was reached. For the specimens subjected to the initial cracking load, four strain gauges 
were symmetrically put onto both sides of each specimen, $5 \mathrm{~mm}$ away from the tip of the pre-notch.

169 Strain gauges were then connected to an Integrated Measurement \& Control (IMC) dynamic date 170 acquisition device. Once a new crack initiated, the measured strains from the strain gauges would 171 drop rapidly due to the sudden release of the stored strain energy at the tip of the pre-crack [22]. 172 Therefore, the initial cracking load could be obtained by gently turning the bolt until the measured 173 strain values dropped quickly. The applied initial cracking loads for the three reference specimens 174 were $2.85 \mathrm{kN}, 2.95 \mathrm{kN}$ and $2.97 \mathrm{kN}$, respectively. During the loading duration, the loads would be 175 adjusted to the pre-set values if they descended by $2 \%$, which caused the increase in the 176 deformation over time. The loading point displacement $(\delta)$ and the crack mouth opening 177 displacement $(C M O D)$ were measured using dial gauges. In addition, three specimens, which were 178 cast at the same time, were kept under the same conditions without loading, named as "aging 179 specimens". The loading point displacement versus time curves of three specimens for two loading 180 levels are shown in Fig. 2, where C-30 and C-ini denote the specimens loaded under $30 \% P_{\max }$ and 181 under the initial cracking load, respectively. After 115 days, the specimens in the creep tests were 182 unloaded from the loading frames and then immediately subjected to the TPB tests. 


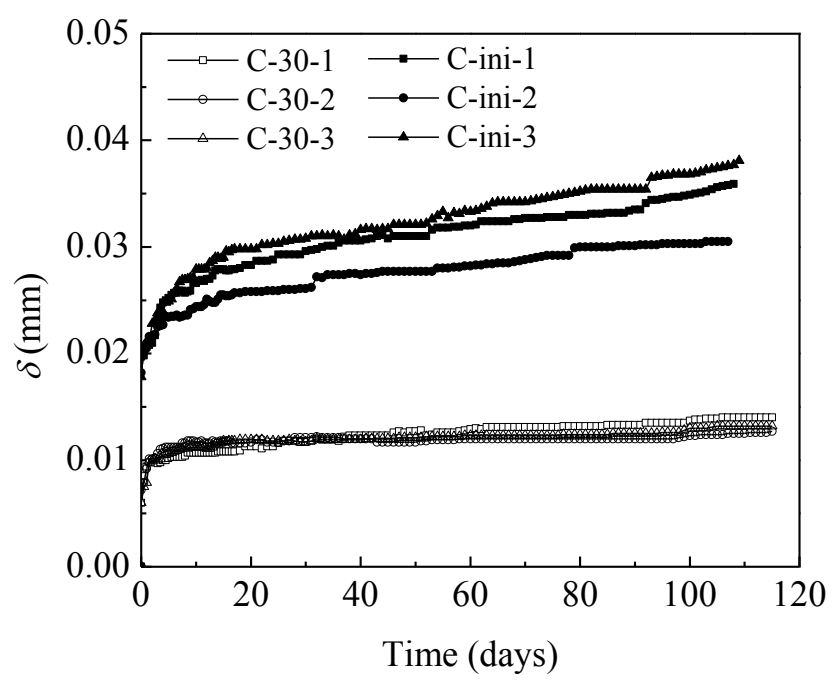

Fig. 2. Loading point displacement versus time curves in the creep tests

\subsection{Three-point bending tests on the pre-notched beams}

187 In order to investigate the effect of sustained loading on the fracture properties of concrete, the TPB 188 tests were performed on the specimens which had been subjected to the creep testing in a $250 \mathrm{kN}$ 189 closed-loop servo MTS testing machine at a displacement rate of $0.048 \mathrm{~mm} / \mathrm{min}$. At the same time, 190 the aging specimens were also tested to for comparing the experimental results after a sustained 191 load with those under a static load. Two clip gauges were used to measure the CMOD, as shown in 192 Fig. 3(a). In addition, to monitor the crack propagation length and crack tip opening displacement 193 (CTOD), four clip gauges were placed equidistantly along the ligament length, as shown in Fig. 3(b). 


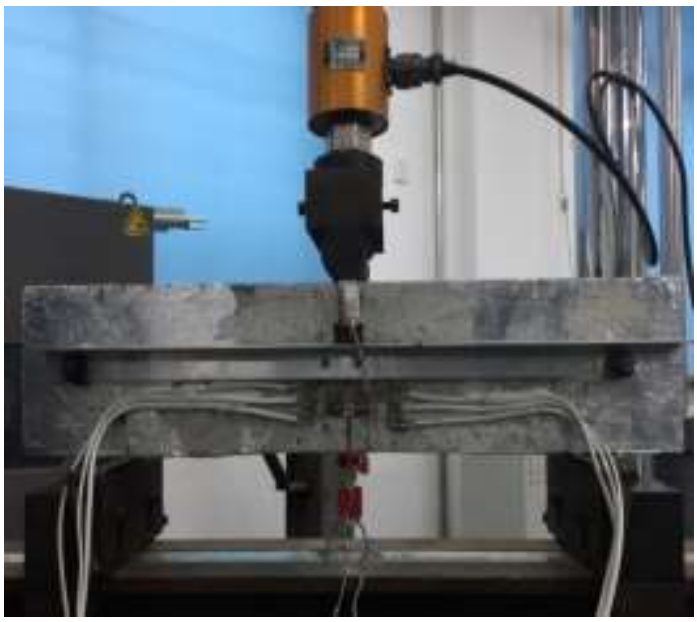

(a) Measuring loading point displacement and CMOD

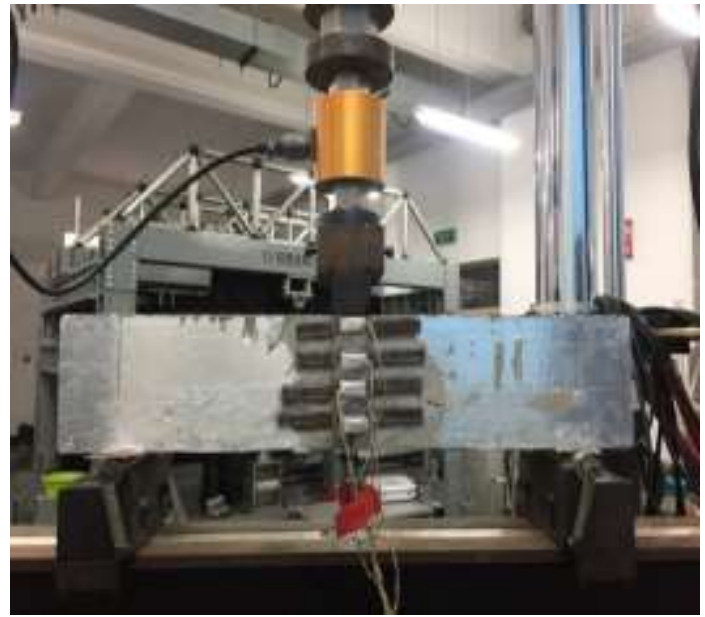

(b) Measuring CTOD

Fig. 3. Experimental set-up for the TPB tests after the creep testing

\section{Test Results and Discussion}

\subsection{Effect of sustained loading on the crack propagation}

From the load point displacement versus time curves in Fig. 2, it can be seen that for the specimens subjected to a sustained loading level of $30 \% P_{\max }$, the displacement increased rapidly in the early loading stage and gradually stabilised with the increase of time. In contrast, for the specimens subjected to a sustained loading level as the initial cracking load, the displacement continuously increased after the early loading stage, which confirms that the secondary creep occurred due to the crack propagation [1]. This indicates that the crack propagation occurred when the concrete specimens were subjected to the early sustained initial cracking load, while the crack would not propagate when the specimens were subjected to the sustained $30 \% P_{\max }$ in the creep tests. In order to determine the crack propagation length during the creep tests, it is assumed that the creep displacements would recover when the specimens subjected to the creep testing were unloaded in the creep tests and then reloaded to the creep loading level in the subsequent TPB tests. Thus, the 
crack propagation length during the creep testing, $a_{\mathrm{f}}$, can be derived from the TPB tests by

211 measuring the $C M O D$ and various crack opening displacements (CODs) along the ligament with 212 four clip gauges as shown in Fig. 3(b). It should be noted that the COD can be employed to denote the 213 opening displacement at any points of the crack surface, while the CMOD only denotes the crack 214 opening displacement at the bottom of a beam.

215 The displacement at the crack initiation, $w_{\text {ini, }}$, could be determined by measuring the CTOD with 216 respect to the initial cracking load on the ageing specimens and was measured as $8.423 \mu \mathrm{m}$. 217 According to the measured values of the $C M O D$ and four CODs along the ligament, an 218 approximately linear distribution of the crack opening displacements could be obtained, as shown in 219 Fig. 4. Based on this relationship, the crack tip could be determined, with its displacement as $w_{\text {ini. }}$. 220 Accordingly, the crack propagation length could also be obtained from the position of the derived 221 crack tip. The values of $a_{\mathrm{f}}$ for the C-ini series specimens are listed in Table 2. It can be seen that the 222 average crack propagation length was determined as $13.50 \mathrm{~mm}$, indicating a significant effect of 223 sustained loading on the crack propagation. The same method was used to determine the critical 224 crack length $a_{\mathrm{c}}$ (see Table 2), which was derived from the CODs corresponding to $P_{\max }$. Meanwhile, 225 to clarify the effect of sustained loading, the values of $a_{\mathrm{c}}$ which were obtained from the 226 experimental investigations and calculated from Eq. (1) based on linear elastic fracture mechanics 227 (LEFM) were compared (see Table 2)

$$
a_{\mathrm{c}}=\frac{2}{\pi}\left(D+H_{0}\right) \arctan \sqrt{\frac{B \cdot E \cdot C M O D_{\mathrm{c}}}{32.6 P_{\max }}-0.1135}-H_{0}
$$
where $B$ and $D$ are the width and depth of the TPB beam, $C M O D_{\mathrm{c}}$ is the critical crack mouth opening displacement, and $H_{0}$ is the thickness of the knife edge and is equal to $3 \mathrm{~mm}$ in this study. 


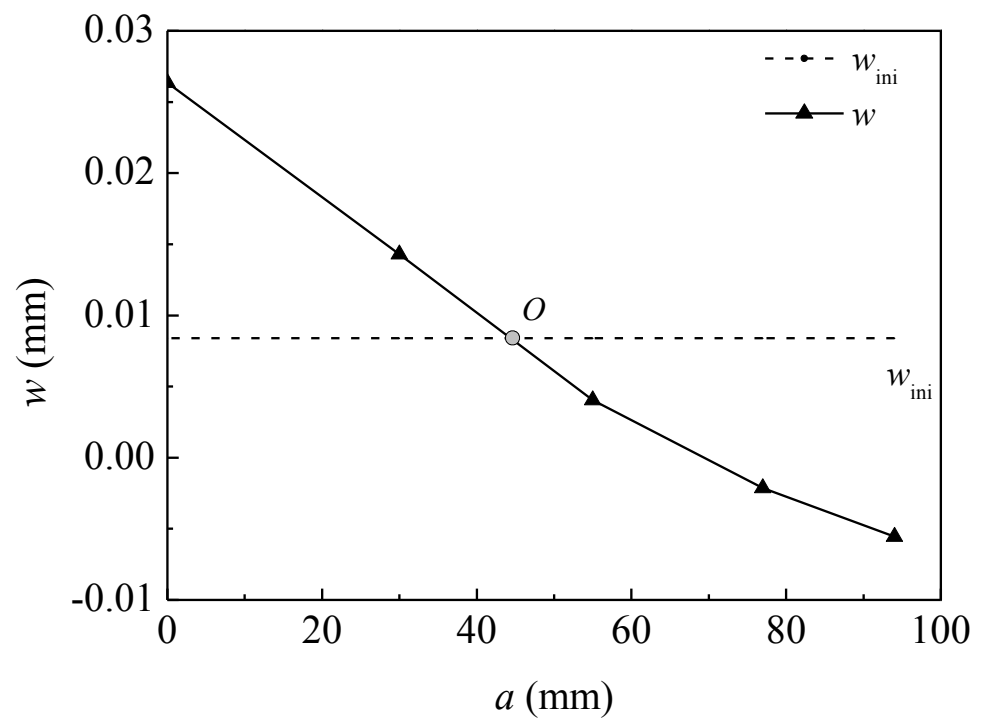

Fig. 4. Determination of the crack tip

Table 2. Experimental results for all specimens

\begin{tabular}{|c|c|c|c|c|c|c|c|}
\hline \multirow{2}{*}{ Specimen } & \multirow{2}{*}{$\begin{array}{c}P_{\text {ini }} \\
(\mathrm{kN})\end{array}$} & \multirow{2}{*}{$\begin{array}{l}P_{\max } \\
(\mathrm{kN})\end{array}$} & \multirow{2}{*}{$\begin{array}{c}a_{\mathrm{f}} \\
(\mathrm{mm})\end{array}$} & \multicolumn{2}{|c|}{$a_{\mathrm{c}}(\mathrm{mm})$} & \multirow{2}{*}{$\begin{array}{c}K_{\mathrm{IC}}^{\mathrm{un}} \\
\left(\mathrm{MPa} \cdot \mathrm{m}^{1 / 2}\right)\end{array}$} & \multirow{2}{*}{$\begin{array}{c}G_{\mathrm{f}} \\
(\mathrm{N} / \mathrm{m})\end{array}$} \\
\hline & & & & Exp. & Eq. (1) & & \\
\hline C-age-1 & 2.66 & 3.56 & 0 & 55.15 & 52.08 & 1.42 & 89.71 \\
\hline C-age-2 & 2.53 & 3.68 & 0 & 50.63 & 48.10 & 1.27 & 109.69 \\
\hline C-age-3 & 2.51 & 3.61 & 0 & 50.25 & 49.13 & 1.22 & 97.44 \\
\hline Mean value & 2.55 & 3.59 & 0 & 52.01 & 49.77 & 1.28 & 98.95 \\
\hline C-30-1 & 2.88 & 3.79 & 0 & 52.78 & 50.98 & 1.31 & 98.22 \\
\hline C-30-2 & 2.61 & 3.25 & 0 & 54.90 & 54.36 & 1.29 & 93.93 \\
\hline Mean value & 2.74 & 3.52 & 0 & 53.84 & 52.67 & 1.30 & 96.08 \\
\hline C-ini-1 & -- & 3.69 & 13.04 & 60.54 & 51.18 & 1.79 & 89.31 \\
\hline C-ini-2 & -- & 3.36 & 14.01 & 57.17 & 52.85 & 1.44 & 95.68 \\
\hline C-ini-3 & -- & 3.37 & 13.40 & 57.69 & 53.81 & 1.47 & 113.73 \\
\hline Mean value & -- & 3.47 & 13.50 & 58.47 & 52.61 & 1.57 & 99.57 \\
\hline
\end{tabular}

235 The results in Table 2 indicate that the values of $a_{\mathrm{c}}$ for the $\mathrm{C}$-age series specimens obtained from the 236 experiments and Eq. (1) are very close to each other, and this validates the test mothed in the 237 current study for determining $a_{\mathrm{c}}$ using the clip gauges. The same case could be observed for the 238 C-30 series specimens, indicating that low sustained loading, e.g. $30 \% P_{\max }$, had almost no effect on 
$a_{\mathrm{c}}$. However, the scenario became different for the C-ini series specimens. The values of $a_{\mathrm{c}}$ obtained

240 from the tests were larger than those derived from Eq. (1), indicating that Eq. (1) based on LEFM

241 may not be appropriate for determining $a_{\mathrm{c}}$ if there is crack propagation during the creep stage. Due

242 to the development of the cracks under the sustained loading, the critical crack lengths of the C-ini

243 series specimens were larger than those for the aging specimens. Compared with the C-age series

244 specimens, the newly expanded crack length was not very large, with the measured mean values of

$245 a_{\mathrm{c}}$ for the C-age and C-ini series specimens as $22.01 \mathrm{~mm}$ and $14.97 \mathrm{~mm}$, respectively.

\subsection{Effect of sustained loading on the fracture properties}

248 The P-CMOD curves of the three series concrete specimens are illustrated in Fig.5. For a vibrant 249 comparison between the three loading conditions, the average curve was used for each loading 250 condition. It can be seen from Fig. 5 that all the peak loads are very close for the specimens 251 subjected to different sustained loadings and the aging specimens, and the mean values of $P_{\max }$ are $2523.59 \mathrm{kN}, 3.52 \mathrm{kN}$ and $3.47 \mathrm{kN}$ for the C-age, C-30 and C-ini series specimens, respectively. The 253 peak load $P_{\max }$ seemed not to be largely affected by the sustained loading applied in this study. 254 Similar conclusions were also drawn by other researchers [11, 12]. After obtaining the peak loads 255 and the critical crack propagation lengths from the tests, the unstable fracture toughness $K_{\mathrm{IC}}^{\text {un }}$ can be 256 calculated using Eq. (2) as [23], where $S$ is the span of the beam and is equalled to $400 \mathrm{~mm}$ in this 257 study

$$
K_{\mathrm{IC}}^{\mathrm{un}}=\frac{3 P_{\max } S}{2 D^{2} B} \sqrt{a_{\mathrm{c}}} F_{2}\left(\frac{a_{\mathrm{c}}}{D}\right)
$$

259 with $F_{2}\left(\frac{a_{\mathrm{c}}}{D}\right)$ to be calculated using Eq. (3) as 


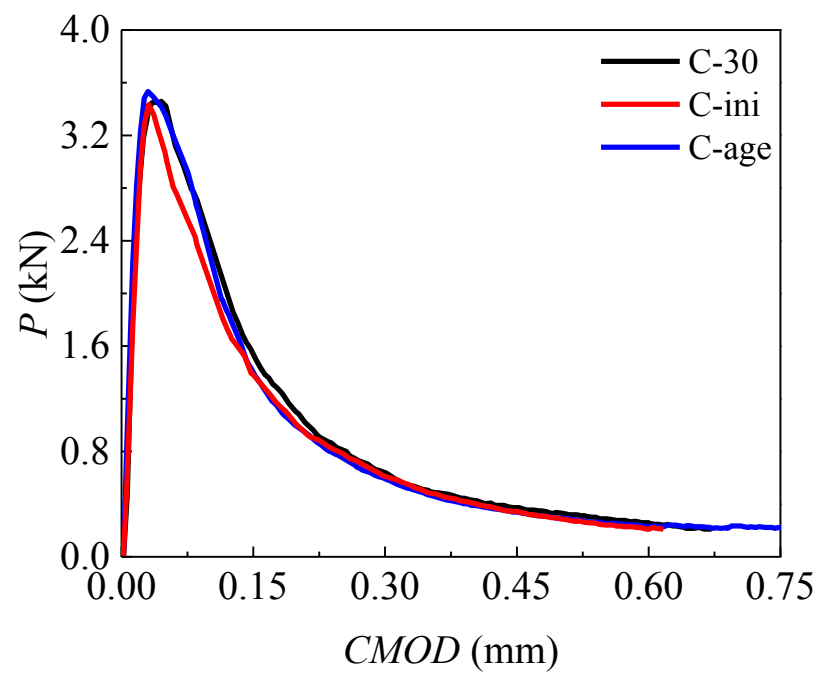

Fig. 5 Average $P-C M O D$ curves for three series specimens

Considering the effects of sustained loading on the fracture properties of concrete, the values of $a_{\mathrm{c}}$ from Eq. (1) might not be appropriate to be used to calculate $K_{\mathrm{IC}}^{\mathrm{un}}$. Alternatively, the obtained values of $a_{\mathrm{c}}$ from the experiment were adopted for calculating $K_{\mathrm{IC}}^{\mathrm{un}}$, as listed in Table 2 . It can be seen that there was a very small difference in $K_{\mathrm{IC}}^{\mathrm{un}}$ between the C-age and C-30 series specimens. However, the mean value of $K_{\mathrm{IC}}^{\mathrm{un}}$ for the C-ini series specimens increased by $22.7 \%$ compared with that for the $\mathrm{C}$-age series specimens. In particular, the mean value of $P_{\max }$ for the $\mathrm{C}$-ini series specimens was smaller than that for the $\mathrm{C}$-age series specimens. This indicates that the low sustained loading did not largely influent the unstable fracture toughness. However, the unstable fracture toughness significantly increased under the high sustained loading, due to the larger critical crack propagation length compared with that under the static loading condition.

Besides the unstable fracture toughness, the fracture energy $G_{\mathrm{f}}$ is also an important fracture parameter for concrete and is defined as the required energy for creating the cracking area. It can be calculated using Eq. (4) as [24] 


$$
G_{\mathrm{f}}=\frac{W_{\mathrm{f}}}{A_{\text {lig }}}=\frac{W_{0}+2 m g \delta_{0}}{B\left(D-a_{0}\right)}
$$

278 where $W_{\mathrm{f}}$ is the total absorbed energy, $A_{\text {lig }}$ is the area of ligament, $W_{0}$ is the area below the measured 279 load-deformation curve, $m g$ is the self-weight of the beam, $\delta_{0}$ is the loading-point displacement at 280 failure, and $a_{0}$ is the initial crack length.

281 For the C-age and C-30 series specimens, there were no crack propagations during the creep testing 282 stage, so that the ligament areas did not change and their fracture energies still could be calculated 283 using Eq. (4). In contrast, for the C-ini series specimens, the ligament areas decreased because the 284 new cracks formed during the creep testing stage. In order to evaluate the effect of these new cracks 285 on the fracture energy, the total energy can be divided into two parts, i.e. the energy dissipated 286 during the creep stage, $W_{\mathrm{c}}$, and the energy dissipated in the subsequent static TPB test, $W_{\mathrm{f}}$. The combination of $W_{\mathrm{c}}$ and $W_{\mathrm{f}}$ governs the complete crack propagation, as illustrated in Fig. 6. Hence, the equation for the fracture energy can be revised as

$$
G_{\mathrm{f}}=\frac{W_{\mathrm{f}}+W_{\mathrm{c}}}{A_{\text {lig }}}=\frac{W_{0}+2 m g\left(\delta_{0}+\delta_{\mathrm{c}}\right)+W_{\mathrm{c}}}{B\left(D-a_{0}\right)}
$$

where $\delta_{\mathrm{c}}$ is the residual displacement in the creep tests.

291 The calculated $G_{\mathrm{f}}$ values using Eq. (4) for the C-age and C-30 series specimens, and Eq. (5) for the C-30 series specimens are all listed in Table 2. It can be seen that, compared with the aging specimens, the sustained loading has slight effect on the fracture energy through the energy dissipated during the creep testing stage. The cohesive stresses were transferred in the FPZ and the energy was dissipated, so that the fracture energy could be directly related to the FPZ evolution. Microscopically, there were no micro-defects, i.e. no micro-cracks or weak planes formed around aggregates under the low sustained loading. In this case, the FPZ evolution should be the same as that under the static loading. In contrast, the micro-cracks would initiate under the high sustained loading, resulting in the slow extension of the FPZ and variations of the crack-bridging stress area. However, the sustained load level applied at the crack initiation in this study was not high enough. 
According to the comparison of the $a_{\mathrm{c}}$ values for the $\mathrm{C}$-age and $\mathrm{C}$-ini series specimens in Table 2, no significant increase was observed. Since the experimental results confirmed that the fracture energy did not change with the sustained load levels, this indicated that the width or height of the FPZ was not affected by the sustained loads applied in this study.

Meanwhile, the mean values of $W_{\mathrm{f}}$ and $W_{\mathrm{c}}$ for the C-ini series specimens were determined as 54.75 $\mathrm{N} \cdot \mathrm{m}$ and $571.7 \mathrm{~N} \cdot \mathrm{m}$, respectively, giving the ratio of $W_{\mathrm{c}} / W_{\mathrm{f}}$ as $9.6 \%$. Therefore, the fracture energy would be underestimated if the LEFM is adopted without considering the crack development during the creep testing stage.

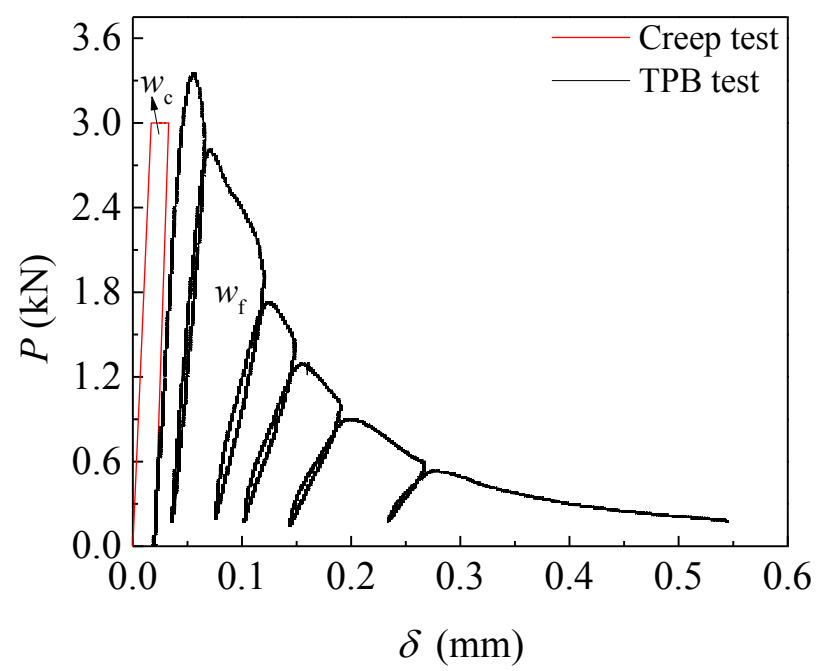

Fig. 6. Load-displacement curves in the creep and static TPB tests

\subsection{Effect of sustained loading on the tension-softening constitutive law}

312 The modified $J$-integral method proposed by Niwa [25] was utilised in this study to investigate the tension-softening constitutive law of concrete after being subjected to the sustained loading. This method has been used to evaluate the tension-softening relationships for polymer cement mortar-concrete [26] and rock-concrete interface [27]. The $J$-integral is defined as the energy available for crack propagation, $E(\delta)$, which can be interpreted as the total absorbed energy of a cracked specimen minus the released elastic energy during unloading process. If both the unloading and reloading paths can be assumed as linear, $E(\delta)$ can be written as 


$$
E(\delta)=\int_{0}^{\delta} P(\delta) d \delta-\frac{1}{2} P(\delta)\left(\delta-\delta_{\mathrm{P}}\right)
$$

where $\delta$ is the displacement for a load $P$, and $\delta_{\mathrm{p}}$ is the residual displacement for a linear unloading-reloading process from the descending branch of the $P$ - $\delta$ curve, see Fig. 7.

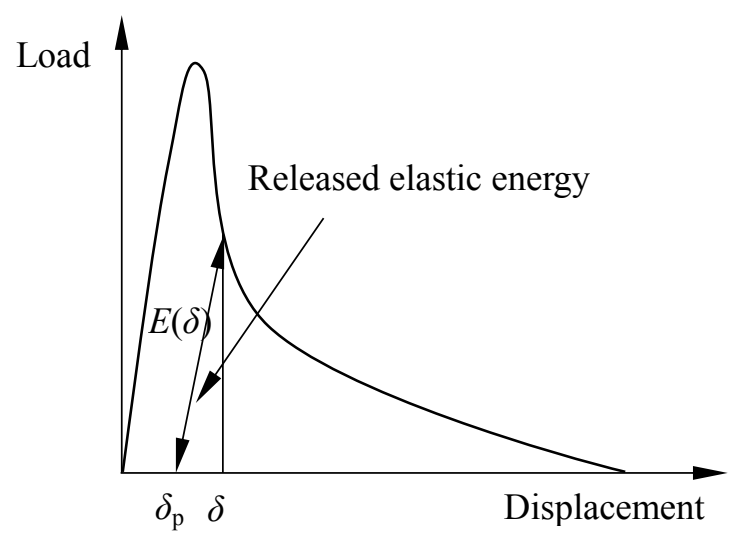

Fig. 7. Illustration of the Modified J integral method

It should be noted that Eq. (6) is only applicable for the specimens without microcracks existing at 327 their pre-crack tips, i.e. the C-age and C-30 series specimens. For the C-ini series specimens, 328 propagations of the microcracks were observed in the creep tests, so that the energy dissipations caused by the microcracks should be considered. Therefore, the cohesive stress $\sigma(w)$ is applied on the FPZ by introducing a tension-softening relationship derived from the test results on the C-age series specimens. Meanwhile, a reduction factor of 0.8 was used to consider the effect of the cohesive stress relaxation [6]. The energy dissipation for the C-ini series specimens includes two parts: one part is for overcoming the effect of the cohesive stress along the microcrack length $a_{\mathrm{f}}$, and 334 another part is for forming the new cracks. Therefore, Eq. (6) for the energy balance can be 335 rewritten as

$$
E(\delta)=\int_{0}^{\delta} P(\delta) d \delta-\frac{1}{2} P(\delta)\left(\delta-\delta_{\mathrm{p}}\right)-0.8 E(\sigma)
$$

337 with $E(\sigma)$ as the energy caused by the cohesive stress along $a_{\mathrm{f}}$ which can be obtained from 


$$
E(\sigma)=B \int_{0}^{\mathrm{a}_{\mathrm{f}}} \int_{\mathrm{w}_{1}(\mathrm{x})}^{\mathrm{w}_{2}(\mathrm{x})} \sigma(w) d w d x+B \int_{0}^{\mathrm{a}_{\mathrm{f}}} \frac{1}{2} \sigma\left(w_{\mathrm{p}}\right)\left(w_{\mathrm{p}}-w_{\mathrm{c}}\right) d x
$$

339 where $\sigma$ is the cohesive stress acting on the fracture process zone, $w$ is the crack width, $x$ is the 340 distance from the pre-crack tip, $w_{\mathrm{p}}$ is the $C T O D$ before unloading in the creep test, $w_{\mathrm{c}}$ is the residual

341 CTOD after unloading in the creep test, $w_{1}(x)=\frac{x}{a_{\mathrm{f}}} w_{\mathrm{p}}, w_{2}(x)=\frac{(a-x)}{a} w$, and $a$ is the crack length.

342 The first term in Eq. (8) denotes the energy caused by the cohesive stress when the applied load in 343 the static TPB test is larger than the sustained loading in the creep test, while the second term 344 denotes the energy when the applied load in the static TPB test is smaller than the sustained loading 345 in the creep test.

346 From the experimental results, the mean values of $w_{\mathrm{p}}, w_{\mathrm{c}}$ and $a_{\mathrm{f}}$ for the C-ini series specimens were 347 obtained as $13.86 \mu \mathrm{m}, 4.78 \mu \mathrm{m}$ and $13.5 \mathrm{~mm}$, respectively. Thus, the tension-softening constitutive 348 law can be determined by establishing the relationships between the crack propagation length $a$, the 349 loading-point displacement $\delta$ and the crack opening displacement $w$.

350 Fig. 8 illustrates the $P-\delta$ curves for Specimens $\mathrm{C}$-age- 1 and $\mathrm{C}$-ini-1 during the complete crack 351 propagation. Based on the unloading-reloading circles in the tests, the $\delta_{\mathrm{p}}-\delta$ relationship can be 352 derived by normalising $\delta_{\mathrm{p}}$ to the maximum displacement $\delta_{\max }$ as (Fig. 9)

$$
\delta_{\mathrm{p}} / \delta_{\max }=\left(\delta / \delta_{\max }\right)^{\eta}
$$

354 where $\eta$ is an empirical coefficient and is obtained by statistically fitting the test results as $1.26,1.37$, 3551.35 for the C-age, C-30 and C-ini series specimens, respectively. 


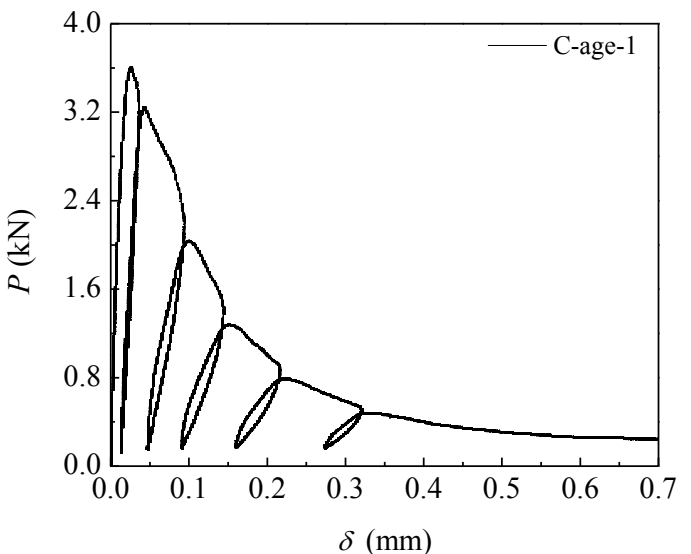

(a) C-age-1

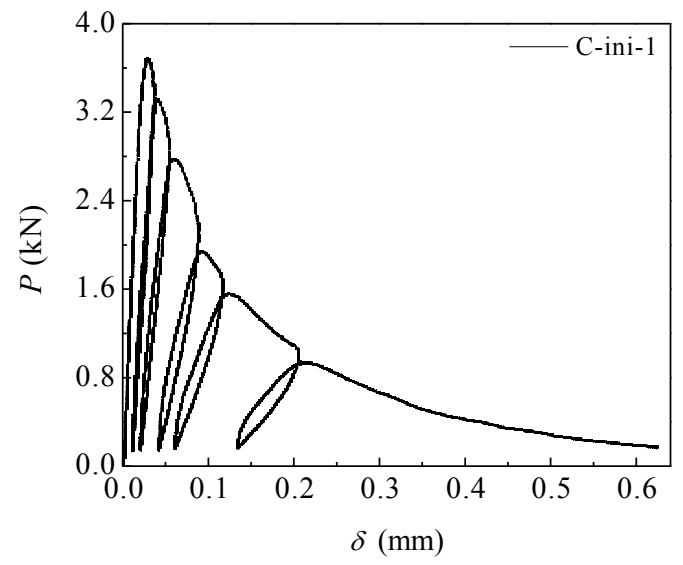

(b) C-ini-1

Fig. 8. Load-displacement curves for different specimens

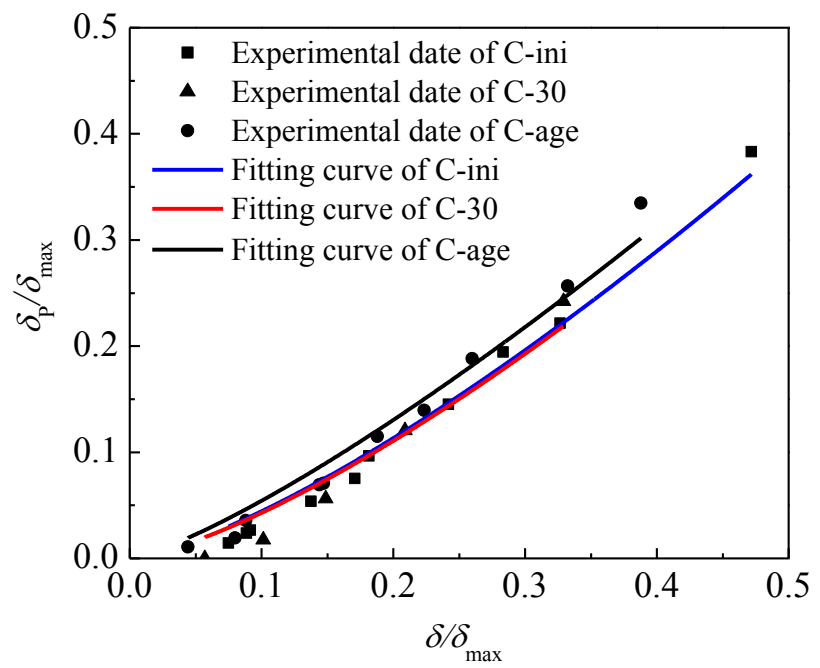

Fig. 9. Relationships between $\delta_{\mathrm{p}} / \delta_{\max }$ and $\delta / \delta_{\max }$ for different specimens

361 If the energy $E(\delta)$ is used to drive the new crack propagation, the tension-softening relationship can be derived as

$$
\sigma(w)=\frac{1}{\Delta a \cdot B}\left[2 E^{\prime}(w)+w E^{\prime \prime}(w)\right]
$$

364 where $E^{\prime}(w)$ and $E^{\prime \prime}(w)$ are the first and second derivatives of the energy $E(w)$. The crack widths at 365 the four equally divided points of the ligament can be measured by using four clip gauges (see Fig. 366 3(b)). Meanwhile, the crack propagation length $\Delta a$ can be derived by measuring the fictitious crack 
tip, as illustrated in Fig. 4. Based on the experimental results, the $\Delta a-w$ relationship (normalized by dividing the ligament height $a_{\max }$ and the maximum crack width $w_{\max }$ ) and the $\Delta a-\delta$ relationship (normalized by dividing $a_{\max }$ and the maximum displacement $\delta_{\max }$ ) can be obtained as follows

$$
\begin{aligned}
& \Delta a / a_{\max }=1-\left(1-\sqrt{w / w_{\max }}\right)^{\gamma} \\
& \Delta a / a_{\max }=1-\left(1-\sqrt{\delta / \delta_{\max }}\right)^{\kappa}
\end{aligned}
$$

372 373 374 375

376

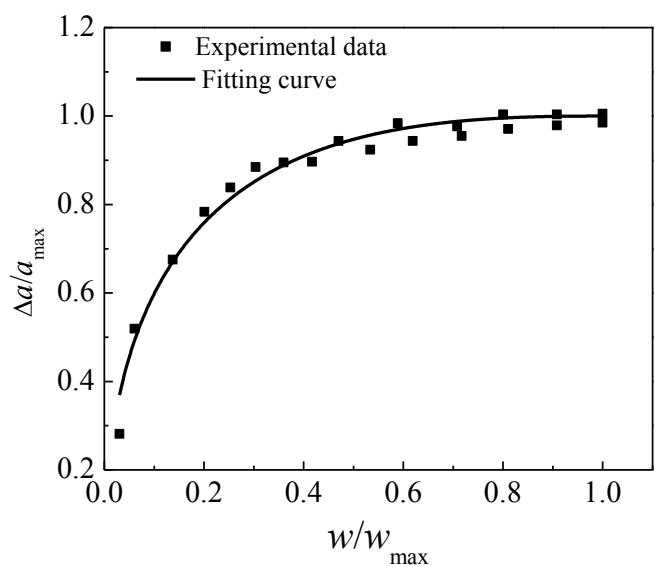

(a) $\Delta a / a_{\max }$ versus $w / w_{\max }$

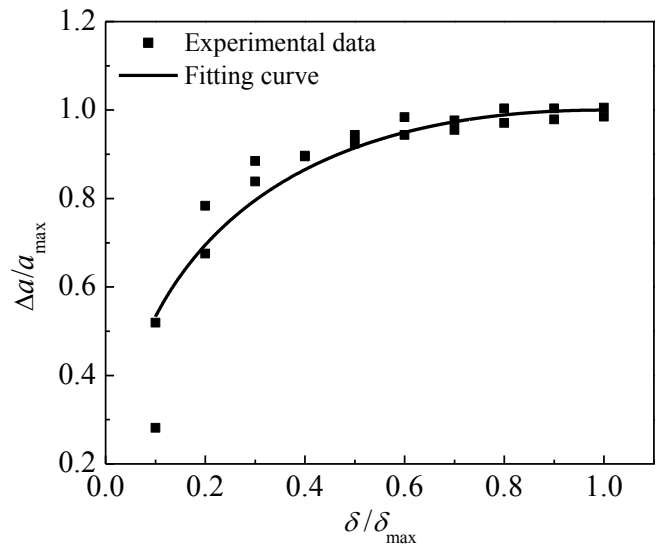

(b) $\Delta a / a_{\max }$ versus $\delta / \delta_{\max }$

Fig. 10. $\Delta a / a_{\max }$ versus $w / w_{\max }$ and $\Delta a / a_{\max }$ versus $\delta / \delta_{\max }$ relationships for the C-ini specimens Finally, an exponential expression for the tension-softening constitutive law can be obtained by substituting Eqs. (9), (11) and (12) into Eq. (8) (also normalized by dividing $f_{\mathrm{t}}$ and $w_{0}$ ) as

$$
\sigma(w)=f_{\mathrm{t}}\left[\left(1+\frac{c_{1}^{3}}{w_{0}^{3}} w^{3}\right) e^{-\frac{\mathrm{c}_{2}}{\mathrm{w}_{0}} w}-\frac{\left(1+c_{1}^{3}\right) e^{-\mathrm{c}_{2}}}{w_{0}} w\right]
$$

where $c_{1}$ and $c_{2}$ are empirical constants. The experimental results indicates that the derived tension softening constitutive laws for the C-age and C-30 series specimens were close to each other, with 
$c_{1}=3, c_{2}=7$ and $w_{0}=0.18 \mathrm{~mm}$ obtained. In contrast, for the $\mathrm{C}$-ini series specimens, $c_{1}=3, c_{2}=6$ and $w_{0}=0.15 \mathrm{~mm}$ were obtained. Furthermore, for practical applications, a bilinear relationship based on the following four parameters, $f_{\mathrm{t}}, \sigma_{\mathrm{s}}, w_{\mathrm{s}}$ and $w_{0}$, can be derived to represent the real tension-softening constitutive law. Once the break-point with the coordinates $\left(\sigma_{\mathrm{s}}, w_{\mathrm{s}}\right)$ is determined, the exponential tension-softening constitutive law can be transformed to the bilinear law by enforcing the same fracture energy $G_{\mathrm{f}}$. Using the method proposed by Wittmann et al [28], the parameters for the bilinear expression of the tension-softening constitutive law are given as follows

$$
\begin{aligned}
& \sigma_{\mathrm{s}}=0.15 f_{\mathrm{t}} \\
& w_{\mathrm{s}}=\alpha G_{\mathrm{f}} / f_{\mathrm{t}} \\
& w_{0}=\beta G_{\mathrm{f}} / f_{\mathrm{t}}
\end{aligned}
$$

where $\alpha$ and $\beta$ are empirical constants. For the C-age and C-30 series specimens, $\alpha=1.2$ and $\beta=5$, while for the $\mathrm{C}$-ini series specimens, $\alpha=1.4$ and $\beta=4$.

Fig. 11 illustrates the exponential and bilinear relationships of $\sigma-w$ for different series specimens. It can be seen that the simplified bilinear relationship is a reasonable approximation of the exponential one, and can reflect the characteristic of the real $\sigma-w$ relationship while a bilinear tension softening constitutive law is more conveniently employed for practical design with much less computational cost. In addition, based on the derived bilinear $\sigma-w$ relationships illustrated in Fig. 11(d), the softening constitutive laws under various conditions show obvious differences. The $\sigma$ - $w$ relationship for the specimens under low load level, i.e. the C-30 series specimens, is similar to the one for the specimens tested in a static condition, i.e. the C-age series specimens. This indicates that the low load level has little influence on the tension-softening constitutive law. However, the scenario is different in the case of high load level. Compared with the static condition, the COD at the breaking point, $w_{\mathrm{s}}$, increased from $1.2 G_{\mathrm{f}} / f_{\mathrm{t}}$ to $1.4 G_{\mathrm{f}} / f_{\mathrm{t}}$ and the free-stress COD, $w_{0}$, decreased from $5 G_{\mathrm{f}} / f_{\mathrm{t}}$ to $4 G_{\mathrm{f}} / f_{\mathrm{t}}$ under the high load level. With the increasing sustained load level, the aggregate interlocking 
over time. Accordingly, compared with the case under static loading, the transference of the

410 cohesive stress in the FPZ would decrease even with the same crack opening displacement under

411 the sustained loading. Therefore, the free-stress crack opening displacement $w_{0}$ would decrease with

412 the increasing sustained load level. Meanwhile, according to the experimental measurements, the

413 fracture energy would not be affected significantly by the sustained loading applied in this study. To

414 ensure the energy balance, $w_{\mathrm{s}}$ would decrease with the increasing $w_{0}$. In summary, this indicates that,

415 under a sustained high load level, a shorter FPZ length could be formed, resulting in the increase in

416 the brittleness of concrete.

417 It should be noted that, according the size effect law [29, 30], the variation of fracture energy was a

418 function of the specimen size and shape. In addition, based on the boundary size model [31, 32], the

419 fracture energy decreased as the crack tip was close to the top surface of a specimen. In this study, the

420 size effect of the fracture energy was not considered when deriving the tensile softening relationship.

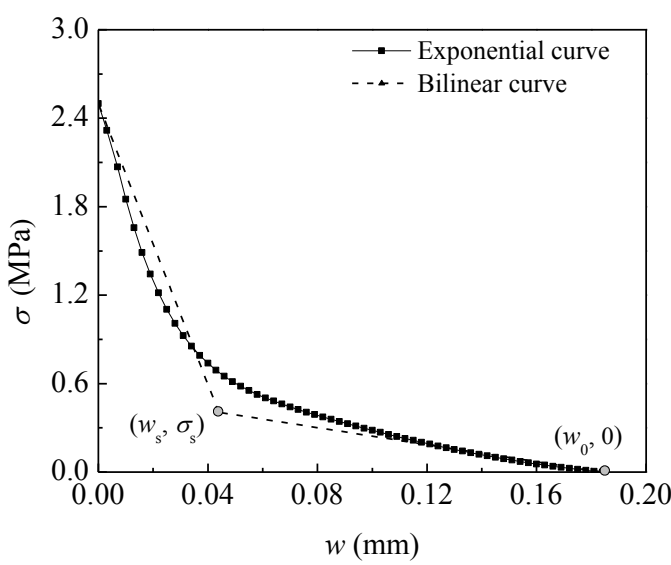

422

(a) Specimen C-age-1

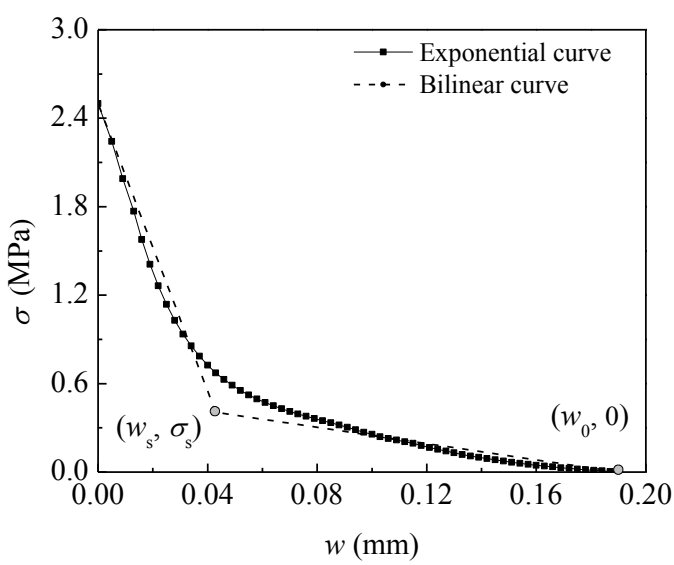

(b) Specimen C-30-1 


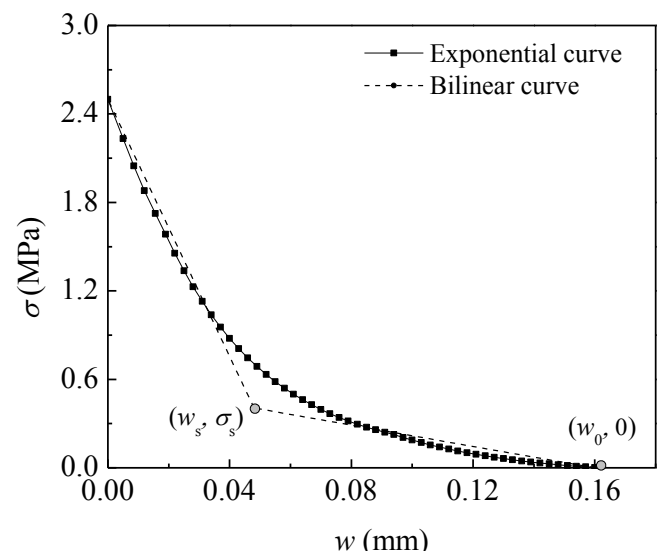

423

(c) Specimen C-ini-1

\section{Conclusions} concrete subjected to low sustained loading.

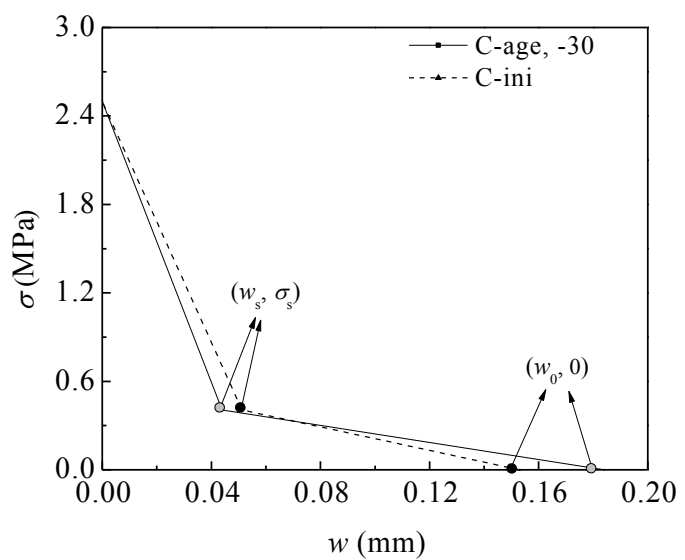

(d) Comparison of bilinear relationships

Fig. 11. Exponential and bilinear $\sigma-w$ relationships

The creep tests were conducted on the concrete specimens for a duration of 115 days by applying the sustained loading levels of $30 \% P_{\max }$ and the initial cracking loads. Thereafter, these specimens were tested under the static TPB. By comparing the critical crack length, the unstable fracture toughness and the fracture energy from the specimens subjected to the creep loading and the aging specimens, the influences of the sustained loading on the fracture properties of concrete were extensively examined. Based on the experimental results, the tension-softening constitutive laws for those TPB specimens were derived using the modified $J$-integral method. According to the experimental and theoretical studies, the following conclusions can be drawn:

1. For low sustained loading levels, e.g. $30 \% P_{\max }$, no crack propagations were observed in the creep tests. Accordingly, the low sustained loading had no effects on the fracture properties of concrete, including the fracture energy, the critical crack length, the initial and unstable fracture toughnesses, and the tension-softening constitutive law. Therefore, the fracture parameters measured from the static loading tests can be utilized to assess the fracture characteristics of

2. For high sustained loading levels, e.g. the initial crack load, the crack propagation length was 
measured as $13.5 \mathrm{~mm}$ on average in the creep tests. Compared with the aging specimens, the critical crack length and the unstable fracture toughness increased for the specimens subjected to the high sustained loading. However, the effect of the high sustained loading on the fracture energy becomes insignificant if considering the crack propagation in the creep stage. In contrast, the fracture energy could be underestimated from the results based on LEFM without considering the developed crack in the creep stage.

3. By introducing the cohesive stress on the creep-induced microcracks into the modified $J$-integral method, the tension-softening constitutive law for the specimens subjected to the creep tests at a high sustained loading level was obtained. For practical applications, the tension-softening constitutive expression was simplified as a bilinear form. Compared with the aging specimens in the static TPB tests, the COD at the breaking point, $w_{\mathrm{s}}$, increased from $1.2 G_{\mathrm{f}} / f_{\mathrm{t}}$ to $1.4 G_{\mathrm{f}} / f_{\mathrm{t}}$, while the free-stress COD, $w_{0}$, decreased from $5 G_{\mathrm{f}} / f_{\mathrm{t}}$ to $4 G_{\mathrm{f}} / f_{\mathrm{t}}$ under the high sustained loading level. Consequently, a shorter FPZ length could be expected, resulting in the increase in the brittleness of concrete.

\section{Acknowledgments}

The authors gratefully acknowledge the financial support of the National Natural Science Foundation of China under the grants of NSFC 51478083, NSFC 51421064 and NSFC 51109026, the Natural

460 Science Foundation of Liaoning Province of China under the grant of 20170540183, and the National Basic Research Program of China (The 973 Program) under the grant of 2015CB057703.

\section{References}

463 [1] Rossi P, Boulay C, Tailhan JL, Martin E, Desnoyers D. Macrocrack propagation in concrete specimens under 464 sustained loading: Study of the physical mechanisms. Cement Concrete Res 2014;63:98-104.

465 [2] Karihaloo BL, Santhikumar S. Application of a visco-elastic tension-softening constitutive model to cracked 466 and ageing concrete. Constr Build Mater 1999;13:15-21. 
[3] Zhou FP. Time-dependent crack growth and fracture in concrete.: Lund University of Technology. Lund, Sweden; 1992.

[4] Bažant ZP. Current status and advances in the theory of creep and interaction with fracture. In: Proceedings of the 5th International RILEM Symposium on Creep and Shrinkage of Concrete. Barcelona, Spain; 1993.

[5] Bažant ZP, Gettu R. Rate effects and load relaxation in static fracture of concrete. ACI Mater J $472 \quad 1992 ; 89: 456-68$.

473 [6] Bažant ZP, Li YN. Cohesive crack with rate-dependent opening and viscoelasticity: I. Mathematical model and 474 scaling. Int J Fracture 1997;86:247-65.

475 [7] Sarkhosh R, Walraven J, Den Uijl J. Time-dependent behavior of cracked concrete beams under sustained loading. In: Proceedings of the 8th International Conference on Fracture Mechanics of Concrete and Concrete Structures. Toledo, Spain; 2013.

[8] Chaimoon K, Attard MM, Tin-Loi F. Crack propagation due to time-dependent creep in quasi-brittle materials under sustained loading. Comput Method Appl M 2008;197:1938-52.

[9] Tailhan JL, Boulay C, Rossi P, Le Maou F, Martin E. Compressive, tensile and bending basic creep behaviours related to the same concrete. Struct Concrete 2013;14:124-30.

[10] Barpi F, Valente S. Failure lifetime of concrete structures under creep and fracture. Mag Concrete Res 2011;63:371-6.

[11] Omar M, Haidar K, Loukili A, Pijaudier-Cabot G. Creep load influence on the residual capacity of concrete structure: Experimental investigation. In: The 5th International Conference on Fracture Mechanics of Concrete and Concrete Structures. Vail, United States; 2004.

[12] Omar M, Loukili A, Pijaudier-Cabot G, Pape YL. Creep-damage coupled effects: Experimental investigation on bending beams with various sizes. J Mater Civil Eng 2009;21:65-72.

[13] Carpinteri A, Valente S, Zhou F, Ferrara G, Melchiorri G. Tensile and flexural creep rupture tests on partially-damaged concrete specimens. Mater Struct 1997;30:269-76.

[14] Saliba J, Loukili A, Grondin F, Regoin J. Experimental study of creep-damage coupling in concrete by acoustic emission technique. Mater Struct 2012;45:1389-401.

[15] Saliba J, Grondin F, Loukili A, Regoin J. Coupling creep and damage in concrete under high sustained loading. In: Proceedings of The 7th International Conference on Fracture Mechanics of Concrete and Concrete Structures. Jeju, Korea; 2010.

[16] Hillerborg A, Modéer M, Petersson PE. Analysis of crack formation and crack growth in concrete by means of fracture mechanics and finite elements. Cement Concrete Res 1976;6:773-81.

[17] Bažant ZP. Creep and damage in concrete. In: Proceedings of The 4th Materials Science of Concrete. Westerville, Ohio; 1995.

500 [18] Hansen E. A visco-elastic fictitious crack model. In: Proceedings of Micromechanics of Quasi-brittle 501 Materials. London; 1992.

502 [19] Carpinteri A, Valente S, Zhou F, Ferrara G, Melchiorri G. Crack propagation in concrete specimens subjected to sustained loads. In: Fracture Mechanics of Concrete Structures. Aedificatio, Freiburg; 1995.

504 [20] Barpi F, Valente S. Creep and fracture in concrete: a fractional order rate approach. Eng Fract Mech 505 2002;70:611-23.

506 [21] Barpi F, Valente S. A fractional order rate approach for modeling concrete structures subjected to creep and fracture. Int J Solids Struct 2004;41:2607-21.

508 [22] Dong W, Wu ZM, Zhou XM. Calculating crack extension resistance of concrete based on a new crack 509 
510 [23] Xu SL, Reinhardt HW. Determination of double-K criterion for crack propagation in quasi-brittle fracture,

511 Part II: Analytical evaluating and practical measuring methods for three-point bending notched beams. Int J 512 Fracture 1999;98:151-77.

513 [24] Petersson PE. Crack growth and development of fracture zones in plain concrete and similar materials. Lund 514 University of Technology. Lund, Sweden; 1981.

515 [25] Niwa J, Sumranwanich T, Tangtermsirikul S. New method to determine tension softening curve of concrete. 516 In: Fracture Mechanics of Concrete Structures Proceedings FRAMCOS-3. Freiburg, Germany; 1998.

517 [26] Zhang DW, Ueda T, Furuuchi H. Fracture mechanisms of polymer cement mortar: Concrete interfaces. J Eng 518 Mech 2012;139:167-76.

519 [27] Dong W, Wu ZM, Zhou XM. Fracture mechanisms of rock-concrete interface: Experimental and numerical. J 520 Eng Mech 2016;142:04016040.

521 [28] Wittmann F, Rokugo K, Brühwiler E, Mihashi H, Simonin P. Fracture energy and strain softening of concrete 522 as determined by means of compact tension specimens. Mater Struct 1988;21:21-32.

523 [29] Bažant ZP, Kazemi MT. Determination of fracture energy, process zone length and brittleness number from 524 size effect, with application to rock and concrete. Int J Fracture 1990; 44:111-131.

525 [30] Hoover CG, Bažant ZP. Universal size-shape effect law based on comprehensive concrete fracture tests. J 526 Eng Mech 2014; 140(3):473-479.

527 [31] Hu XZ. Fracture energy and fracture process zone. Mater Struct 1992; 25:319-326.

528 [32] Hu XZ, Guan JF, Wang YS, Keating A and Yang ST. Comparison of boundary and size effect models based 529 on new developments. Eng Fract Mech 2017;175:146-167. 